\title{
Analysis of Nokia's Decline from Marketing Perspective
}

\author{
Jianzhong Jia, Yuchan Yin \\ School of Business Administration, South China University of Technology, Guangzhou, China \\ Email: 844375919@qq.com
}

Received 28 September 2015; accepted 24 October 2015; published 27 October 2015

Copyright (C) 2015 by authors and Scientific Research Publishing Inc.

This work is licensed under the Creative Commons Attribution International License (CC BY). http://creativecommons.org/licenses/by/4.0/

c) (i) Open Access

\begin{abstract}
Nokia was a synonym for the mobile phone industry for a long time; however, when it came into the era of smart phones, the former leader was under an awkward situation. Nokia sold its mobile phone business to Microsoft on September 3, 2013. A company following Kodak with the legendary color failed in the impact of the new technology revolution. This was a typical case of the subversion of an industry; therefore, the author believed that it was necessary to analyze the process. This paper studied Nokia's decline mainly from the three parts. First of all, looking back Nokia's development process from the glory to the decline, it can be divided into three stages: the transition period, the peak period and the decline period, followed by analyzing the reasons of its decline from three parts: Nokia executives' grasp for the market, the company's business strategy and business cooperation, and finally analyzing its inspiration for modern enterprises from the marketing perspective.
\end{abstract}

\section{Keywords}

Nokia, Market Grasp, Operational Tactic, Cooperation

\section{Introduction}

Nokia, the leader of mobile phone industry, was acquired by Microsoft in September 2013. Nokia's mobile phone business would be owned by Microsoft since then. Microsoft announced in Monday (September 2nd) evening that it would buy most of Nokia's mobile phone business at the price of 3.79 billion euros (about 5 billion dollars), and buy Nokia's patent license with 1.65 billion euros (about 2.18 billion dollars) in addition, so the total price of the transaction was about 5.44 billion euros (about 7.17 billion dollars). Once the transaction was completed, 32,000 employees of Nokia, including 4700 employees in Finland and about 18,300 manufacturing employees, would join Microsoft; Microsoft would get Nokia's department of device and service, includ- 
ing mobile phones, smart devices and the leading design team [1].

As the leader in the mobile phone industry, Nokia was bought by Microsoft in September 2013, and Nokia's mobile phone business had been owned by Microsoft since then. Nokia, as an enterprise with a long history of one hundred years old, was founded in 1865 and developed to the peak in 2007. It took nearly a hundred years to accumulate its brand. But it was acquired by Microsoft in 2013; it took only several years for the brand to decline. Nokia's decline was an irreparable loss for Nokia itself, while it was a lesson that it was worth learning for other companies. Both business world and academic circles had been analyzing the fall of Nokia from different aspects in order to obtain some valuable experience and lessons.

\section{Literature Review}

In academic circles, different experts and scholars have analyzed the decline of Nokia from different perspectives. Fu, Z. S. [2] had analyzed Nokia's failure according to impracticability of Nokia phone's operating system. Yi, M. and Zheng, Z. Q. had resolved Nokia's failure by comparing Nokia with Apple. Yi, M. [3] thought that the main reason why Nokia lost to Apple was pursuing technological innovation blindly, and neglecting the most important business model innovation. Zheng, Z. Q. [4] discussed the importance of the correct grasp of the consumer need from consumer purchasing behavior characteristics of different periods. Yang, K. [5] believed that Nokia wasn't flexible, and led the advantage to barriers, thus blamed Nokia's failure to over pursuit of cost control. Zeng, F. P. [6] discussed the factors affecting the success of the enterprise taking Nokia as an example. It mainly analyzed from four aspects: product innovation, management mechanism, marketing models and marketing channels. Wang, Y. W. [7] explored the impact of organizational practice update on the competitiveness of Nokia and Apple by using case study method in the process of 2G era changing into 3G era. Wang, W. H. [8] paid much attention to the strategies Nokia implemented in the past, pointed out the company's existing problems and put forward practical suggestions on the base of analyzing its financial data, financial performance and financial policy. Shang, T. M. [9] considered that Nokia made a lot of errors in the process of strategic transformation, and caused the transformation sure to succeed into a doomed failure. Specifically, Nokia failed to adapt to the competition of mobile Internet era, but still hoped bring the experience and order of the old era into the new era. While some critics believed that the quality of Nokia's mobile phone was the essential issues. In this paper, we analyzed the reasons of the decline of Nokia from the perspective of marketing, and put forward some suggestions for the contemporary enterprises.

\section{From Glory to Decline-The Development of Nokia}

As a veteran mobile phone companies, Nokia has experienced a total of three transformations: from rubber, paper to cable, from cable to mobile phones, from mobile phone to mobile Internet over a hundred years of business process since 1865 . The two former transformations can be said to be very perfect, and did make a great contribution to the development of Nokia. However, in the era of mobile Internet, Nokia in the third transformation has been out of orbit, and has not launched star products meeting the requirements of mobile Internet. Facing the rapid development of Apple and Android phones, it seemed that Nokia was a bit powerless, and has already lost the leadership style of the mobile phone industry.

\subsection{Nokia’s Transition from Diversification to Specialization (1865-1998)}

Before 1992, Nokia adopted the business tactic that was highly cross-industry and diversified, and had 34 subsidiaries in 10 different industries and 108 areas. When Nokia was in the situation of full loss in 1992, the company's board of directors hired Ollila as president of the company. Ollila immediately gave up the diversification tactic, adjusted the business structure drastically, narrowed the scope of operation, abandoned non-core business, and sold 71 enterprises. At last, there were only two groups, mobile phone and network, and Nokia began its professional road from now on.

Before 1998, Motorola is the world's largest mobile phone manufacturer, and Nokia has been in hot pursuit of it. In the 6 years of the implementation of the professional tactic, Nokia's rate of increase increment has remained at around $50 \%$, becoming the world's largest mobile communications manufacturers. Nokia produced the 100,000,000th mobile phone in 1998, and then become the world's largest mobile phone manufacturers instead of Motorola. 


\subsection{On the Road of Professionalization and Being No. 1 (1998-2007)}

Since Nokia exceeded Motorola in 1998, its market share soared in a few years. The year of 2006 was a milestone for the development of Nokia in China. Nokia's annual sales and exports in China were more than 10 billion euro with net sales being more than 5.3 billion euro and exports amounting to 4.8 billion euro. China has become the largest market for Nokia in the world.

The year of 2007 was Nokia's harvest year, because its global market share reached 40\%; in China, the largest market, the market share of this year was also more than 30\% (Economics New, Jan. 2012). So far, in China and the global market, there is no such crazy data. However, the glory of Nokia seemed to be drawing to a close during this year.

\subsection{From the Peak to the Decline and Final Acquisition of Microsoft (2007-2013)}

The smart phone operating system Android, Google released in 2008, became a new market reform. The smart phone storm led by iPhone and Android has proved to be market mainstream. For the first time, Nokia didn't occupy the first position of the mobile phone market share, the ranking dropped to the third. What's worse, Nokia's share of the smart phone market in 2011 has dropped from 33\% in 2010 to 14\%, far lower than Apple and Samsung.

According the "mobile Internet users behavior research survey in 2012" released by CNNIC, 53\% of Nokia's mobile phone users planned to buy smart phone in the future s, of which $43.3 \%$ chose the Android system, $28.6 \%$ picked IOS system. Massive customer switching meant that the future of Nokia's mobile phone market share would further decline, Nokia was facing not only how to compete for new users, but also how to retain the old users. Nokia user's future choice of cellphone system was shown in [10] Figure 1.

IResearch Consulting's report released in December 2012 showed that for the domestic market of mobile phone sales, Samsung became the market leader accounting for 32.3\%, Apple (14.3\%), HUAWEI (12.5\%), Lenovo (7.3\%) and HTC (5.9\%) followed. Nokia, whose ranking has slipped out of the top three since September, occupied 5.9\% in the market. Sales share of each mobile phone brand in December 2012 in Chinese market as shown in [11] Figure 2.

Nokia has suffered a series of attacks since 2012. It has been pressed by many events, including several landmark events Nokia announced 10,000 layoffs globally on June 15, 2012, besides Nokia sold headquarters building at 17 million euro on December 5, 2012; finally Nokia sold the company's mobile phone business to Microsoft on September 3, 2013.

\section{Analysis of the Reasons for Nokia's Decline}

Nokia had a long history of manufacturing mobile phone, and not only its manufacturing standard but also its management leadership reached a fairly high level. And during its strategic transformation Nokia developed corresponding auxiliary products to assist the sales of mobile phones, such as, Nokia put forward the concept of mobile Internet and developed the Internet brand Ovi in early 2007; Nokia reached a strategic cooperation rela-

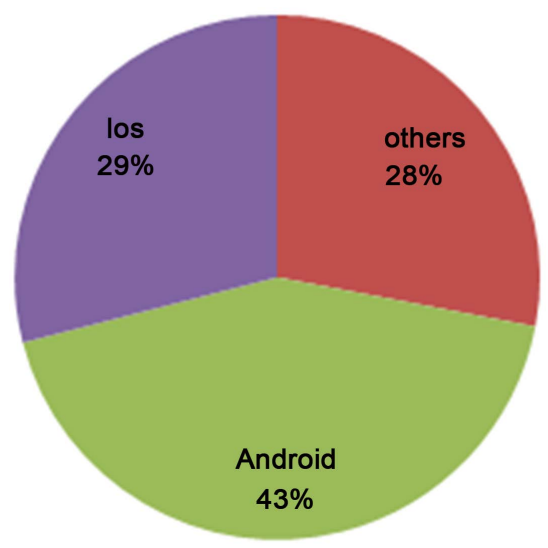

Figure 1. Nokia users' future choice of mobile phone system. 


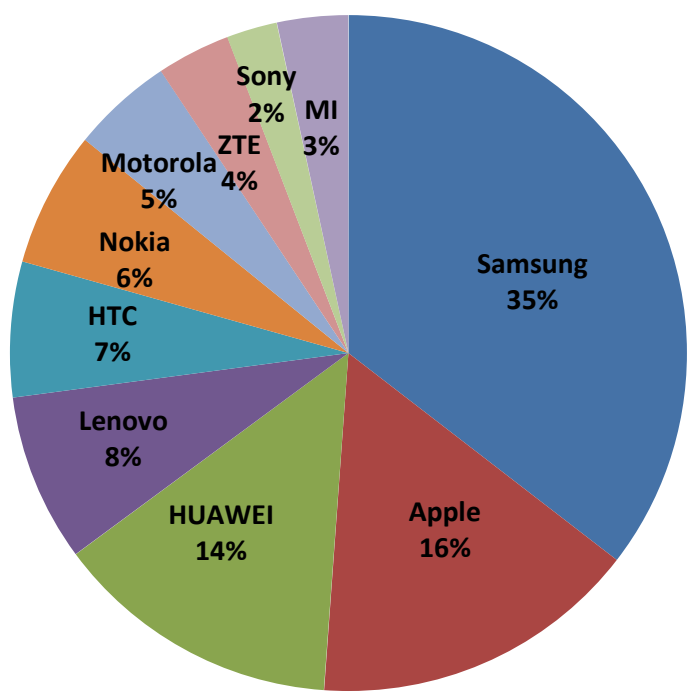

Figure 2. Sales share of each mobile phone brand in December 2012.

tionship with Microsoft in February 2011, to obtain success with the help of the cooperative development. However, Nokia's equipment and services department was acquired by Microsoft on September 3, 2013, and the equipment and services sector was mainly responsible for the mobile phone business. Since then, Nokia as a mobile phone brand exited the stage of history, and went over course of its mobile phone development. Throughout the history of its development, I analyzed Nokia's decline mainly from the following three aspects.

\subsection{Nokia's Executives Didn't Grasp the Market Accurately}

The first mobile phone entered people's life as a tool of calling, and was mainly dedicated to mobile phone calls to make up for the lack of fixed telephone. People at that day could absolutely not imagine that they could use mobile phones to listen to music, watch videos, surf the Internet, play games and even go shopping. Nevertheless, with the progress and development of science and technology, smart phones appeared in people's life, powerful functional machine was unable to meet the new needs of people, cellphone manufacturers began to realize that mobile phone must be updated.

When the mobile phone was popular in the market dozens of years ago, the majority of consumers paid more attention to the actual benefits of mobile phones such as battery life and cellphones' drop number due to the economic level limit, their purchase behaviors were generally more rational, objective and real; however, people's income increased significantly in twenty-first century, buying mobile phone was no longer as carefully as in the past, mobile phone was more considered as entertainment tools, the purchase behavior is more emotional and initiative.

In the face of the changes of the market and consumer demand, Nokia still adopted the technology-oriented and product-oriented strategies to guide the innovation of products, continued to strengthen the inherent properties of Nokia mobile phone blindly: for example, Nokia was trying to make its cellphone hard to broken, then exploited new ways to extend its battery's life span, and increased the pixel of mobile phones to reach the cameras' standard [4]. The executives focus on products and technology a lot, so as to ignore that the needs of consumers have changed with the market showing different characteristics. Decision-making that wasn't based on consumer's demand lead Nokia not only to separate itself from the market, ignore the real needs of consumers, but also to do much idle work.

\subsection{There Is a Deviation in the Business Tactic of the Company}

The traditional 4P theory (including product, price, place, promotion) transformed into 4C theory (including Consumer, Cost, Communication, Convenience) gradually. It meant that companies should pay more attention to the products as well as the consumer needs, so that the product innovation must take the real needs of consumers into account. Like the mobile phone, what do consumers really care about, the hardware or software? 
Nokia has valued the hardware business a lot and neglected the software business over a long period of time. The company continued to carry out technological innovation so as to cause Nokia mobile phones to be a magic that couldn't be broken, but ignored the fundamental problems, the incompatibility and closure property of the operating system. The operating system of Nokia mobile phone was Symbian, which was very popular in the machine age and did earn a lot of market share for Nokia. However, in the era of smart phones, Symbian's drawbacks gradually emerged and eventually became the biggest hinder for the development of Nokia mobile phone. Firstly, Symbian system is not compatible, not only having the multiple incompatible versions, but also having no ability of backward compatibility, which lead to Saipan 7 application couldn't run on Symbian 8, and increased research and development costs virtually. Secondly, Saipan's shortcoming such as process solidify and clumsy problem caused it not to support touch screen, multimedia and new operation interface, which meant Nokia mobile phones were at a disadvantage in the smart phone market. Finally, Saipan's insisting on 2G development didn't adapt to current 3G development momentum.

However, even if Symbian's faults were well aware, Nokia did not give it up, only because Symbian was rather mature and brought Nokia huge profits. If Nokia could adopt an open attitude to treat the innovation of the operating system and cooperated with Google Android, it must have developed one operating system that was more suitable for smart phone system than the Android and Symbian system, thus Nokia may haven't come to such a situation.

\subsection{Nokia Was Lack of Teamwork}

Any marketing strategy should guarantee that the company and other enterprises could achieve a win-win situation. Nowadays, trying to control the market share of a certain industry through the technology monopoly to obtain high profits was not possible in the context of product and service homogenization. The biggest mistake that Nokia made was refusing to cooperate with other mobile phone manufacturers in its business process.

Symbian system itself is a closed system, which on one hand can form barriers to prevent other Handset manufacturers from entering the market Nokia has occupied; on the other hand lead Nokia to lose sight of the changes of outside and thus missed the best chance of reform. In order to obtain the high monopoly profits, Nokia refused to work with other mobile phone manufacturers and gave this closure property to the extreme. Refusing to cooperate did keep its own inherent market and achieve the monopoly to a certain extent, while the Symbian system was very difficult to develop and the application were few, which made it hardly possible to meet the consumers' demand; at the same time Nokia's strong style also forced other mobile phone manufacturers seek to cooperate with each other. Owing to Android system was a fully open system, which can be applied to any phone, so far many mobile phone manufacturers have joined the Android camp, such as Samsung, HUAWEI, HTC, SONY Ericsson, Coolpad and ZTE, etc. Many Android camp companies' cooperation was not only enough to compete with Nokia, but also could enrich and improve the Android system develop more applications meeting the needs of consumers.

\section{The Inspiration to Modern Enterprises}

\subsection{The Executives Need to Accurately Grasp the Market Trend}

In the era of rapid development of science and technology, the replacement speed of products as well as service was rapidly increasing. All customer needs, even the core needs that firms were most familiar with, would inevitably change. Therefore, enterprises should keep close to customers, and tried their best to study them, take the change trend of their demands and satisfy them. Remember not to use the old marketing information, even though they have been proven effective in the last years, because they might not be able to resonate with the current customers. Just like the mobile phone industry, consumer demand for mobile phones has shifted from functionality and durability to intelligence and entertaining, thus strengthening the phone's hardware facilities like Nokia was wrong, on the contrary, it should seek to develop and improve the software, the focus should also be shifted from the call quality to the number of the applications and simplicity of operation.

Consumers' demand and desire is the subjective feeling to consumption, and could be effected by a lot of factors, such as the characteristics of the products itself, service quality, brand influence, the affordability, the market trends, etc., so it would be extremely difficult to determine which one was more important. This required 
all companies to always stand in a leading position of the times, follow the market trends, have an insight into the changes happened in the entire consumer market. On the one hand, enterprises can acquire the general situation of the past consumer demand through access to second-hand information about the development of the industry; on the other hand, enterprises could get better understanding of market changes through market research to obtain the latest first-hand data of trends in consumer demand changes.

\subsection{The Companies Should Make the Right Business Tactic}

Business tactic means that the reaction that one enterprise takes to form their own advantages and create space for survival and development by considering its advantages and disadvantages in the competitive environment. Business tactic can't remain unchanged, on the contrary, it must be adjusted to the changes of the internal conditions and the external environment. Besides, Business tactic is related to future development of the enterprise. So it is significant for any company to investigate and analyze the external environment and internal conditions of enterprises, define the position of the enterprise in the market competition, and eventually have a clear direction about how to enhance its own strength.

Enterprises should abandon those programs that are not very suitable for the enterprise project quickly, as Symbian has been unable to meet the smart phone requirements and unable to meet consumer demand, when they have recognized the market trend. Any firms intending to occupy a share in the field of smart phones should learn from Samsung, who withdrew from Saipan to Android camp in the early development of the smart phone. As the result turns out, Samsung's timely abandoning Symbian made it now the largest smart phone maker in Android camp, and Nokia's seeing the situation distinctly made it gradually lose the king of hill position, even had no right to speak in smart phone market, and eventually ended up being acquired by Microsoft.

This is a revelation for modern enterprises, on the one hand to seize the opportunity to give up the business tactic not adaptable to the market and its own development path early, on the other hand, to find a new way suitable for the market and its own development prospects [7]. Companies must understand that the business tactic of a business is its business strategy and have a significant impact on the enterprise, whether in the short term or in the long term.

\subsection{The Enterprises Should Be More Cooperative than Competitive}

The current world is an open world, the resources, technology, management experience and so on have to be shared under the rapid development and popularization of the Internet. There is no isolated enterprise, any enterprise is having a variety of contact with other enterprises, and it is proved that only cooperation is the source and power of long-term development of enterprises. Any enterprise refusing to cooperate must be faced with the fact that it will be defeated by other united companies in the same industry. Just like in the smart phone industry, a number of mobile phone manufacturers in the Android camp grabbed Nokia's market share to an empty.

So Nokia should have cooperated with other mobile phone manufacturers to broaden the entire mobile phone market, in this way each company's share of profits will increase accordingly, and the profit is far more than its previous monopoly profits. But Nokia was unwilling to abandon the high monopoly profits Symbian brought, worse still it was not willing to share the profits with other enterprises and rejected to collaborate with Android. It may also be said that Nokia's crisis was blamed for its conservation, because its rejecting to cooperate forced other handset vendors to associate with each other, and the smart phone market share was seized step by step.

So the current enterprises must have a win-win idea and put it into action. Take a small step back is to take a big step forward, and win-win does not mean to give up their own interests, but this is a more intelligent and forward-looking profit thinking, it not only helps companies to preserve their own in the competitive environment, but also establish business partnerships to seek support for the future development.

\section{Conclusion}

This paper first introduced the background of Nokia's acquisition by Microsoft, then proposed the research direction of this paper based on the interviews by studying the problems, and followed by giving a brief account of the three stages of Nokia's development. After that, this paper analyzed the Nokia's decline from three aspects: Nokia's executives didn't grasp the market accurately; there was a deviation in the business tactic of the company; Nokia was lack of teamwork. Finally, this paper put forward the targeted marketing strategies on the 
above three problems of Nokia.

\section{References}

[1] http://www.cnii.com.cn/mobileinternet/2013-09/03/content_1214896.htm

[2] Fu, Z.S. (2010) Nokia Smart Phone Satisfaction Is Not High Operating System Closed or the Main Reason. communication Information

[3] Yi, M. (2011) When Nokia Met Apple. Business Management, 12, 60-62.

[4] Zheng, Z.Q. (2013) Influence of Utilitarianism and Hedonism on Purchase Behavior in Mobile Phone-Nokia and Apple as an Example. Journal of Liaoning Medical College, 10, 50-52.

[5] Yang. K. (2013) Nokia, the Giant Dying from the Advantage. East China Science and Technology, 9, 62-63.

[6] Zeng, F.P. (2012) Key of the Success of the Enterprise as an Example to Nokia. China Trading, 15, 60-63.

[7] Wang, Y.W., Ma, J., Wu, X.F. and Liu, S.C. (2012) Introduction of New Technology, Organizational Practice Update, Enterprise Competitiveness Research-Based on Nokia, Apple Case Comparison Research. Science and Technology Management, 11, 150-159.

[8] Wang, W.H. (2013) Superstar's Death—Financial and Strategic Analysis of the Nokia Failure. Master's Thesis, Xiamen University, Xiamen.

[9] Shang, T.M. (2012) To Live or To Die, It’s a Question for Nokia. State-Owned Enterprise, 10.

[10] China Internet Network Information Center (CNNIC) (2012) China Mobile Internet Users Online Behavior Research Report. 11.

[11] IResearch (2012) China Mobile Network Retail Market Testing Report. 12 